\title{
Visceral adipose tissue-derived serine protease inhibitor inhibits interleukin-1 $\beta$-induced catabolic and inflammatory responses in murine chondrocytes
}

\author{
JIA-PENG BAO, LI-FENG JIANG, JING LI, WEI-PING CHEN, PENG-FEI HU and LI-DONG WU \\ Department of Orthopedics Surgery, The Second Hospital of Medical College, \\ Zhejiang University, Hangzhou, Zhejiang 310009, P.R. China
}

Received November 28, 2013; Accepted May 30, 2014

DOI: $10.3892 / \mathrm{mmr} .2014 .2478$

\begin{abstract}
Visceral adipose tissue-derived serine protease inhibitor (vaspin) is a newly identified member of the adipocytokine family, whose precise role in chondrocyte metabolism remains to be elucidated. The aim of the present study was to investigate the effect of vaspin on chondrocytes. The cell viability and the cytotoxicity of vaspin in chondrocytes were examined. Furthermore, the gene expression of matrix metalloproteinases-2 and -9, a disintegrin and metalloproteinase with thrombospondin motifs 4 and 5 and cathepsin D was also examined, as well as the protein production of cyclooxygenase-2, prostaglandin E2 and inducible nitrous oxide synthase following treatment with different concentrations of vaspin in the absence or presence of interleukin-1-beta (IL-1 $\beta$ ). In addition, the protein levels of the inhibitor of nuclear factor- $\kappa \mathrm{B}(\mathrm{I} \kappa \mathrm{B}-\alpha)$ and the phosphorylation of nuclear factor kappa $\mathrm{B}(\mathrm{NF}-\kappa \mathrm{B})$ were investigated. Vaspin was not able to stimulate the proliferation of chondrocytes and demonstrated no significant cytotoxic effect at concentrations of $10-500 \mathrm{ng} / \mathrm{ml}$ following coincubation for 24 and $48 \mathrm{~h}$. However, vaspin inhibited IL-1 $\beta$-induced production of catabolic factors and inflammatory mediators in chondrocytes, and also suppressed the phosphorylation of NF- $\kappa \mathrm{B}$ and the degradation of IкB- $\alpha$. The data from the present study suggested that vaspin has a protective effect in chondrocyte metabolism and is an important factor in the pathophysiology of osteoarthritis.
\end{abstract}

Correspondence to: Professor Li-Dong Wu, Department of Orthopedics Surgery, The Second Hospital of Medical College, Zhejiang University, 88 Jiefang Road, Hangzhou, Zhejiang 310009, P.R. China

E-mail:1dwu@yahoo.com

Key words: vaspin, osteoarthritis, chondrocytes

\section{Introduction}

Osteoarthritis (OA) is a chronic cartilage and joint disease among elderly individuals, primarily characterized by articular cartilage breakdown, osteophyte formation, subchondral sclerosis and synovium alterations (1). Cartilage degeneration, which impairs function and causes pain and disability, is known to contribute to major structural alterations in the joint. Inflammatory cytokines, including interleukin-1 beta (IL-1 $\beta$ ), cyclooxygenase-2 (COX-2), prostaglandin E2 $\left(\mathrm{PGE}_{2}\right)$ and nitric oxide (NO) as well as catabolic factors, including matrix metalloproteinases (MMPs), a disintegrin and metalloprotease with thrombospondin motifs (ADAMTS) and cathepsins are major mediators of disturbed chondrocyte function and cartilage degeneration (2). In addition, age, gender, injury and obesity are considered to be major risk factors for the progression of OA (3). Previous studies have revealed that not only the knee and hip OA were closely associated with obesity, but also the non-weight bearing joints, such as the hand OA, were more frequent in obese individuals $(4,5)$, however, the reasons for this remain to be elucidated. Furthermore, adipokines secreted by white adipose tissue are considered to be a link between obesity and OA, particularly in non-weight bearing joints (6). Accumulating evidence suggested that adipokines, including leptin, adiponectin, resistin, visfatin and apelin exert pro-inflammatory/anti-inflammatory and catabolic/anabolic roles during the pathophysiology of OA (7).

Visceral adipose tissue-derived serine protease inhibitor (vaspin) was identified as a novel adipocytokine, which has been found to be expressed in the visceral adipose tissue of Otsuka Long-Evans Tokushima Fatty rats at an age when obesity and insulin resistance peaked (8). Several human tissues, including adipose tissue $(9,10)$, skin (11), stomach (12), liver and pancreas (13) have been found to express vaspin. Serum vaspin levels were paradoxically elevated in human subjects with diabetes and obesity (14). Notably, several studies demonstrated novel links between vaspin and arthritis $(15,16)$. Ozgen et al (15) found that serum vaspin levels were higher in rheumatoid arthritis (RA) compared with healthy controls. Furthermore, the serum vaspin level was increased following glucocorticoid treatment but unaffected following adalimumab treatment in RA patients (16). In addition, another 
Table I. Primers of targeted genes.

\begin{tabular}{|c|c|c|c|}
\hline Targeted gene & Sequence $\left(5^{\prime}-3^{\prime}\right)^{\mathrm{a}}$ & Amplicon length (bp) & Accession number \\
\hline \multirow[t]{2}{*}{ MMP-2 } & F: AGGATGGAGGCACGATTGG & & \\
\hline & R: CTTGATGATGGGCGACGGT & 111 & NM031054 \\
\hline \multirow{2}{*}{ MMP-9 } & F: ACCCCATGTATCACTACCACGAG & & \\
\hline & R: TCAGGTTTAGAGCCACGACCAT & 91 & NM031055 \\
\hline \multirow[t]{2}{*}{ ADAMTS-4 } & F: GCCAGCAACCGAGGTCCCATA & & \\
\hline & R: CCACCAGTGTCTCCACGAATCTAC & 113 & XM001053685 \\
\hline \multirow[t]{2}{*}{ ADAMTS-5 } & F: GGGGTCAGTGTTCTCGCTCTTG & & \\
\hline & R: GCCGTTAGGTGGGCAGGGTAT & 146 & AY382879 \\
\hline \multirow[t]{2}{*}{ Cathepsin D } & F: CAGGCADATCGTAAGTGGC & & \\
\hline & R: GTCGTGGAAAGGACAGTTGG & 51 & NM134334 \\
\hline \multirow[t]{2}{*}{$18 \mathrm{~S}$} & F: TTGACGGAAGGGCACCA & & \\
\hline & R: CAGACAAATCGCTCCACCAA & 165 & NR046237.1 \\
\hline
\end{tabular}

${ }^{\mathrm{a}} \mathrm{F}$, forward; R, reverse.

study (17) identified increased levels of vaspin in the synovial fluid of patients with RA compared with those with OA. These data suggest a possible role of vaspin in the pathophysiology of arthritis.

Previously, Kamio et al (18) demonstrated that vaspin inhibited receptor activator of nuclear factor- $\kappa \mathrm{B}$ ligand (RANKL)-induced osteoclastogenesis in RAW264.7 cells and bone marrow cells (BMCs). Vaspin also inhibited the RANKL-induced upregulation of MMP-9 and cathepsin K in RAW264.7 cells (18), which suggested that vaspin was important in bone metabolism. However, to the best of our knowledge, there are currently no studies investigating the effect of vaspin on chondrocytes. The aim of the present study was to detect the role of vaspin in chondrocytes. Initially, the effect of vaspin on normal chondrocyte viability and gene expression of MMP-2, MMP-9, ADAMTS-4, ADAMTS-5 and cathepsin was assessed, as well as the effect of vaspin on the secretion of $\mathrm{COX}-2, \mathrm{PGE}_{2}$ and iNOS. Secondly, the effect of vaspin on IL-1 $\beta$-induced catabolic and inflammatory responses in chondrocytes was evaluated. In addition, the present study investigated the effect of vaspin on the IL-1 $\beta$-induced nuclear factor-kappaB (NF- $\mathrm{B})$ signaling pathway activation in chondrocytes.

\section{Materials and methods}

Isolation and culture of primary rat articular chondrocytes. Rat articular chondrocytes for primary culture were isolated from the knee joints of 4-week-old Sprague-Dawley rats obtained from The Animal Center of Zhejiang University (Hangzhou, China). The study was approved by the ethics committee of The Second Hospital of Medical College, Zhejiang University (Hangzhou, China). The harvested cartilage samples were cut into $1 \mathrm{~mm}^{3}$ cubes and digested for $0.5 \mathrm{~h}$ with $0.2 \%$ pronase (Sigma, St. Louis, MO, USA), followed by digestion for $4 \mathrm{~h}$ with $0.1 \%$ collagenase (Sigma) at $37^{\circ} \mathrm{C}$. The released chondrocytes were cultured in $25 \mathrm{~cm}^{2}$ culture flasks in Dulbecco's modified Eagle's medium supplemented with $10 \%$ fetal bovine serum, $100 \mathrm{U} / \mathrm{ml}$ penicillin and $100 \mu \mathrm{g} / \mathrm{ml}$ strepto- mycin (Invitrogen Life Technologies, Carlsbad, CA, USA) in a $5 \% \mathrm{CO}_{2}$ atmosphere at $37^{\circ} \mathrm{C}$. Chondrocytes were passaged at a ratio of $1: 3$ with $0.05 \%$ trypsin (Life Technologies, Hangzhou, China) up to $80 \%$ confluence. Cultured chondrocytes at passage 3 were used to avoid loss of chondrocyte phenotype with successive passages.

Assessment of cell viability. Cytotoxicity of vaspin to chondrocytes was evaluated using a Cell Counting kit-8 (CCK-8; Dojindo Laboratories, Kumamoto, Japan) according to the manufacturer's instructions. Chondrocytes were cultured in 96-well plates at a density of $2 \times 10^{4}$ cells $/ \mathrm{cm}^{3}$ and the cytotoxicity was assessed in the presence of increasing concentrations of vaspin $(0,10,50,100,250$ and $500 \mathrm{ng} / \mathrm{ml})$. Cell proliferation was examined 24 and $48 \mathrm{~h}$ after the addition of vaspin. At the indicated time points, $100 \mu \mathrm{l}$ fresh medium and $10 \mu \mathrm{l}$ CCK- 8 solution were added to each well of the plate, and the chondrocytes were incubated for $2 \mathrm{~h}$. Absorbance of $450 \mathrm{~nm}$ was measured using a microplate reader (Bio-Rad, Hercules, CA, USA).

Quantitative polymerase chain reaction ( $q P C R$ ) analysis of MMP-2, MMP-9, ADAMTS-4, ADAMTS-5 and cathepsin D. Rat chondrocytes were treated with various concentrations of vaspin $(0,10,50,100,250$ and $500 \mathrm{ng} / \mathrm{ml})$ for $24 \mathrm{~h}$, while other chondrocytes were pretreated with various concentrations of vaspin for $1 \mathrm{~h}$ prior to treatment with IL-1 $\beta(10 \mathrm{ng} / \mathrm{ml})$ for $24 \mathrm{~h}$. The gene expression was analyzed by qPCR. Total RNA was isolated from monolayer chondrocytes using TRIzol reagent (Invitrogen Life Technologies) according to the manufacturer's instructions, dissolved in diethylpyrocarbonate-treated water and stored at $-80^{\circ} \mathrm{C}$ prior to use. Total RNA $(1 \mu \mathrm{g})$ was used for synthesis of cDNA by reverse transcription, using the PrimeScript-RT reagent kit (Takara Bio., Inc., Shiga, Japan), and the reverse transcription reaction product was analyzed by qPCR using the SYBR Premix Ex Taq (Takara Bio., Inc.), according to the manufacturer's instructions. The target gene primers used are shown in Table I. A parallel amplification 
of 18S (NR046237.1) was performed to normalize expression data of the targeted gene transcript. Relative expression level data were analyzed using the $2^{-\Delta \Delta \mathrm{Ct}}$ method.

ELISA analysis of COX-2, PGE 2 and iNOS in the culture medium. Rat chondrocytes were treated with various concentrations of vaspin $(0,10,50,100,250$ and $500 \mathrm{ng} / \mathrm{ml})$ for $24 \mathrm{~h}$, while other chondrocytes were pretreated with various concentrations of vaspin for $1 \mathrm{~h}$ prior to IL- $1 \beta$ treatment $(10 \mathrm{ng} / \mathrm{ml})$ for $24 \mathrm{~h}$. The effect of IL-1 $\beta$ and/or vaspin on the levels of $\mathrm{COX}-2, \mathrm{PGE}_{2}$ and iNOS secreted by articular chondrocytes in the culture medium was further detected by commercially available ELISA kits (R\&D Systems, Inc., Minneapolis, MN, USA) according to the manufacturer's instructions. All assays were performed in duplicate.

Western blot analysis of $p-N F-\kappa B$ and $I \kappa B-\alpha$. Confluent articular chondrocytes were incubated in serum-free medium for $24 \mathrm{~h}$. The chondrocytes were pre-treated with various doses of vaspin $(0,10,50,100,250$ and $500 \mathrm{ng} / \mathrm{ml})$ for $1 \mathrm{~h}$ prior to IL-1 $\beta(10 \mathrm{ng} / \mathrm{ml})$ for $24 \mathrm{~h}$. All chondrocytes were washed twice with ice-cold phosphate-buffered saline, harvested using a scraper and then the cytoplasmic proteins were isolated using an extraction kit (Beyotime Institute of Biotechnology, Jiangsu, China). Samples were subjected to sodium dodecyl sulfate polyacrylamide gel electrophoresis, transferred onto nitrocellulose filters and probed with the following primary antibodies: p-NF- $\kappa \mathrm{B}$ and $\mathrm{I} \kappa \mathrm{B}-\alpha$ (rabbit monoclonal anti-mouse; Cell Signaling Technology, Hangzhou, China) overnight at $4^{\circ} \mathrm{C}$. The membranes were washed and incubated for $1 \mathrm{~h}$ at room temperature with horseradish peroxidase-linked secondary antibodies (goat monoclonal anti-rabbit). Detection was performed with enhanced chemiluminescence using a commercially available kit according to the manufacturer's instructions (Cell Signaling Technology) and the density of each band was measured by densitometry using Quantity One Software (Bio-Rad Laboratories Inc., Munich, Germany).

Statistical analysis. All experiments were performed three times using independent samples. Data are expressed as the mean \pm standard deviation. Statistical analyses were performed using SPSS 19.0 for Windows software (SPSS, Inc., Chicago, IL, USA). Statistical significance was determined using Student's t-test and one-way analysis of variance. $\mathrm{P}<0.05$ was considered to indicate a statistically significant difference.

\section{Results}

Effects of vaspin on chondrocyte viability. In order to rule out direct cytotoxic effects, a CCK-8 test was performed. As shown in Fig. 1, the results indicated that vaspin at concentrations of $10,50,100,250$ and $500 \mathrm{ng} / \mathrm{ml}$ after 24 and $48 \mathrm{~h}$ of culture demonstrated no significant cytotoxic effect on chondrocytes. However, no chondrocyte proliferation effects of vaspin were identified at any of these concentrations.

Effects of vaspin on the production of catabolic factors and inflammatory cytokines in rat chondrocytes. Following treatment with vaspin for $24 \mathrm{~h}$, the expression of MMP-2, MMP-9, ADAMTS-4, ADAMTS-5 and cathepsin D were detected

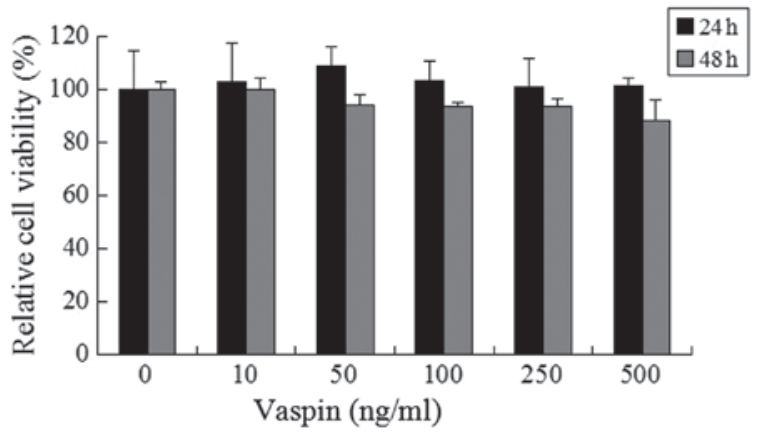

Figure 1. Effects of vaspin on cell viability. Chondrocytes were initially plated in each well of a 96-well plate and treated with different concentrations of vaspin $(0,10,50,100,250$ and $500 \mathrm{ng} / \mathrm{ml})$ for 24 and $48 \mathrm{~h}$. The cells were then evaluated using a cell-counting-kit- 8 assay. Values are expressed as the mean \pm standard deviation of three independent experiments. Vaspin, visceral adipose tissue-derived serine protease inhibitor.

using qPCR. As shown in Fig. 2, vaspin (10, 50, 100, 250 and $500 \mathrm{ng} / \mathrm{ml}$ ) alone did not affect the gene expression of these catabolic factors. As noted in Fig. 3, the secretion levels of COX-2, $\mathrm{PGE}_{2}$ and iNOS in chondrocytes decreased following treatment with vaspin, however, not significantly.

Effects of vaspin on IL-1 $\beta$-induced MMP-2, MMP-9, ADAMTS-4, ADAMTS-5 and cathepsin D mRNA in rat chondrocytes. Following stimulation with IL-1 $\beta$ (10 ng/ml; Fig. 4), rat chondrocytes demonstrated marked upregulation of MMP-2, MMP-9, ADAMTS-4, ADAMTS-5 and cathepsin D. Vaspin inhibited MMP-2, MMP-9, ADAMTS-5 and cathepsin D but not ADAMTS-4 in low concentrations and failed to inhibit the production of IL-1 $\beta$-induced catabolic factors in high concentrations.

Effects of vaspin on IL-1 $\beta$-induced COX-2, $\mathrm{PGE}_{2}$ and iNOS production in rat chondrocytes. Following stimulation with IL-1 $\left(10 \mathrm{ng} / \mathrm{ml}\right.$; Fig. 3), the production of COX-2, $\mathrm{PGE}_{2}$ and iNOS from the culture medium of rat chondrocytes significantly increased. Vaspin inhibited all these inflammatory cytokines in a dose-dependent manner.

Effects of vaspin on the $N F-\kappa B$ pathway induced by treatment with $I L-1 \beta$ in rat chondrocytes. In order to investigate the mechanisms of vaspin mediated-inhibition of IL-1 $\beta$-induced catabolic and inflammatory responses, cultured rat chondrocytes were treated with either IL- $1 \beta$ alone or with various concentrations of vaspin for $24 \mathrm{~h}$. The phosphorylation of

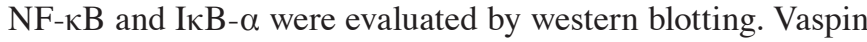
pretreatment at different concentrations $(10,50,100,250$ and $500 \mathrm{ng} / \mathrm{ml}$ ), prior to IL-1 $\beta$ stimulation, inhibited IL-1 $\beta$-induced NF- $\kappa B$ phosphorylation in a dose-dependent manner (Fig. 5). In addition, the degradation of IкB- $\alpha$ induced by IL- $1 \beta$ was also inhibited by vaspin (Fig. 5).

\section{Discussion}

Vaspin has been suggested to be a 'good' adipokine similar to adiponectin (19). Administration of vaspin to obese mice improved glucose tolerance and elevated insulin sensitivity (20). A study by Kadoglou et al demonstrated a protective 

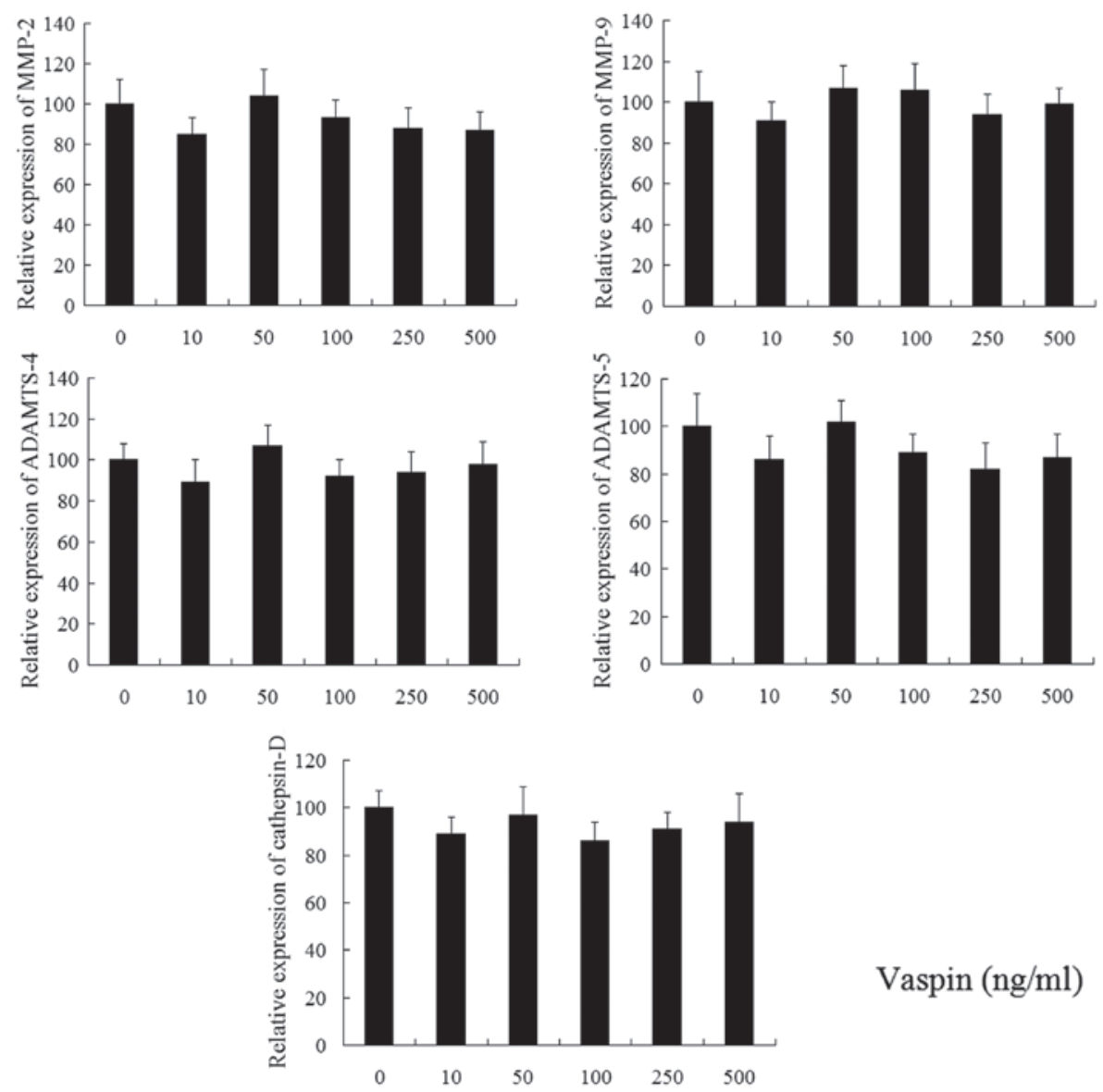

$\operatorname{Vaspin}(\mathrm{ng} / \mathrm{ml})$

Figure 2. Effects of vaspin on the gene expression of MMP-2, MMP-9, ADAMTS-4, ADAMTS-5 and cathepsin D. All the mRNA expression levels were not affected by vaspin at different concentrations. The results are representative of three experiments. MMP, matrix metalloproteinase; ADAMTS, a disintegrin and metalloproteinase with thrombospondin motif; vaspin, visceral adipose tissue-derived serine protease inhibitor.

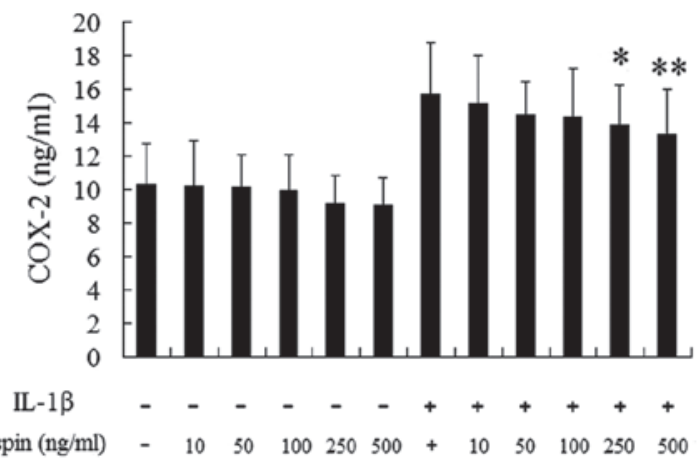

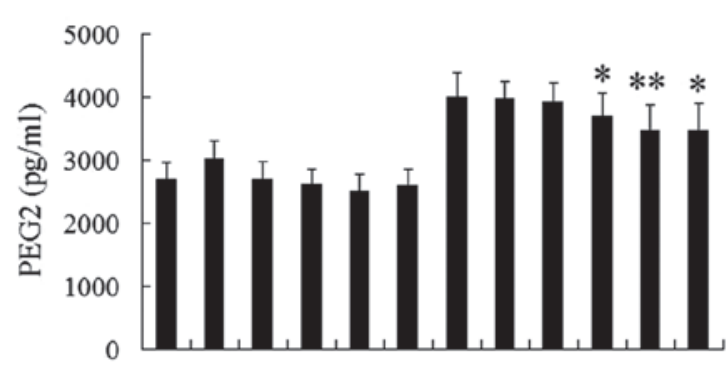

IL-1 $\beta$

Vaspin (ng

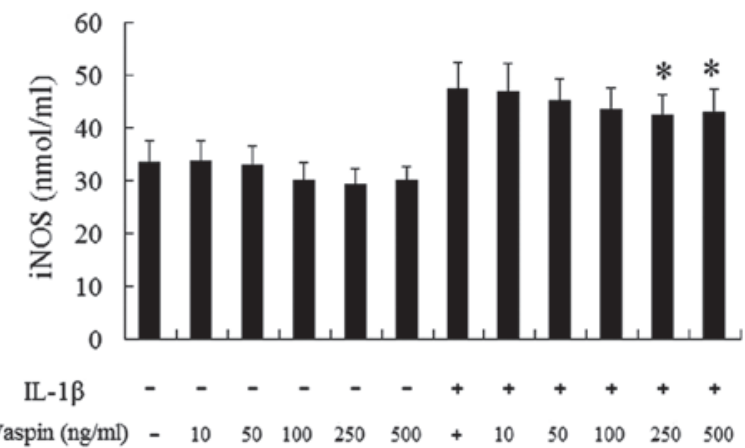

Figure 3. Effects of vaspin on COX-2, $\mathrm{PGE}_{2}$ and iNOS production. Chondrocytes were treated with concentrations of vaspin $(0,10,50,100,250 \mathrm{and} 500 \mathrm{ng} / \mathrm{ml})$ for $1 \mathrm{~h}$ prior to treatment with IL- $1 \beta(10 \mathrm{ng} / \mathrm{ml})$ for $24 \mathrm{~h}$. The results are representative of three experiments. ${ }^{*} \mathrm{P}<0.05$ and ${ }^{* *} \mathrm{P}<0.01$, vaspin-treated chondrocytes compared with chondrocytes stimulated with IL- $1 \beta$ alone. COX-2, cyclooxygenase-2; PGE $_{2}$ prostaglandin E2; iNOS, inducible nitrous oxide synthase; vaspin, visceral adipose tissue-derived serine protease inhibitor; IL-1 $\beta$, interleukin-1 $\beta$. 


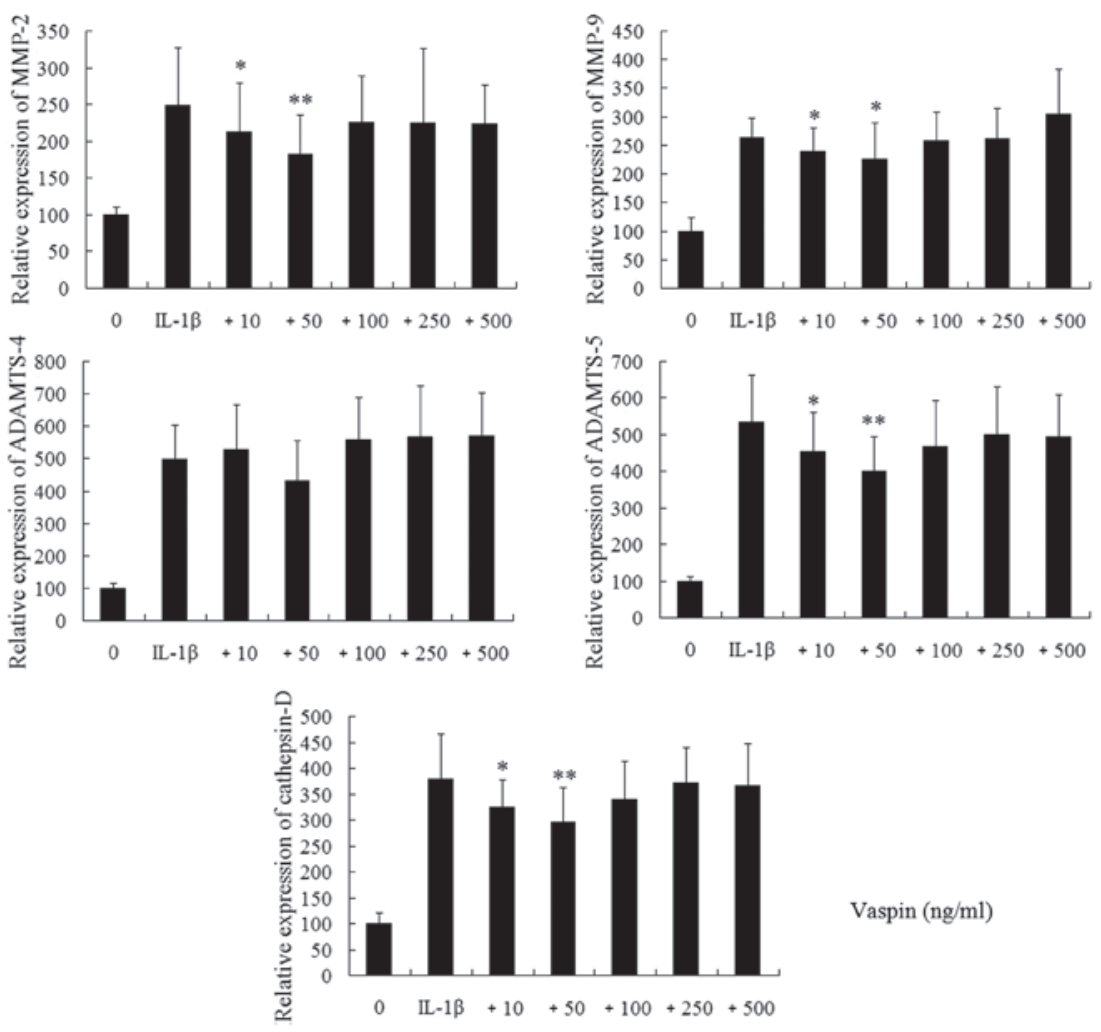

Figure 4. Effects of vaspin on IL-1 $\beta$-induced gene expression of MMP-2, MMP-9, ADAMTS-4, ADAMTS-5 and cathepsin D in chondrocytes. Chondrocytes were pretreated with various concentrations of vaspin $(0,10,50,100,250$ and $500 \mathrm{ng} / \mathrm{ml})$ for $1 \mathrm{~h}$ prior to treatment with IL-1 $\beta$ (10 ng/ml) for $24 \mathrm{~h}$. The results are representative of three experiments. ${ }^{*} \mathrm{P}<0.05$ and ${ }^{* * *} \mathrm{P}<0.01$, vaspin-treated chondrocytes compared with chondrocytes stimulated with IL-1 $\beta$ alone. MMP, matrix metalloproteinase; ADAMTS, a disintegrin and metalloproteinase with thrombospondin motif; vaspin, visceral adipose tissue-derived serine protease inhibitor.

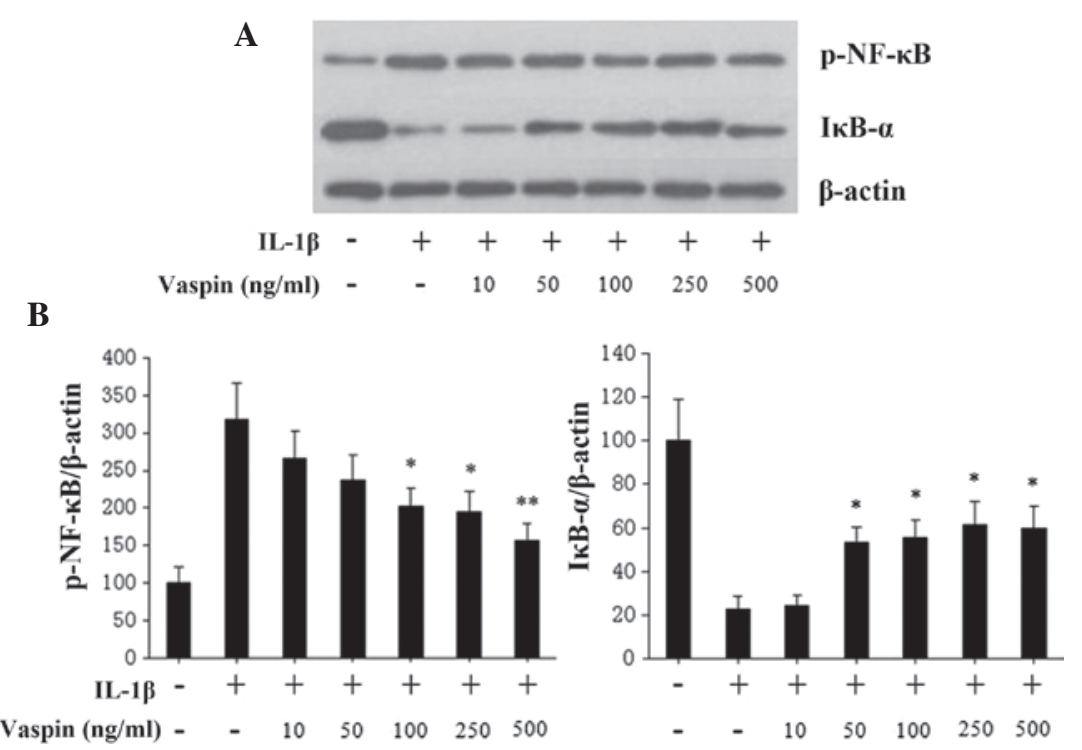

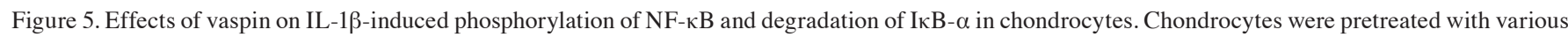
concentrations of vaspin $(0,10,50,100,250$ and $500 \mathrm{ng} / \mathrm{ml})$ for $1 \mathrm{~h}$ prior to treatment with IL- $1 \beta(10 \mathrm{ng} / \mathrm{ml})$ for $24 \mathrm{~h}$. The phosphorylation of NF- $\mathrm{BB}$ and the expression of IкB- $\alpha$ were determined by (A) western blot analysis. (B) Densitometry data was also assessed. The results are representative of three experiments. ${ }^{*} \mathrm{P}<0.05$ and ${ }^{* *} \mathrm{P}<0.01$, vaspin-treated chondrocytes compared with chondrocytes stimulated with IL-1 $\beta$ alone. IL-1 $\beta$, interleukin- $1 \beta$; NF- $\kappa \mathrm{B}$, nuclear factor-kappaB; IкB- $\alpha$, inhibitor of kappa B- $\alpha$; vaspin, visceral adipose tissue-derived serine protease inhibitor.

effect of vaspin against atherosclerosis and cardiovascular events (21). In addition, several studies have demonstrated that vaspin may act as an anti-apoptotic and anti-inflammatory cytokine in certain cell types (22-24). Phalitakul et al (22) demonstrated that vaspin inhibited methylglyoxal-induced endothelial cell apoptosis by preventing caspase-3 activation via the inhibition of NADPH oxidase-derived reactive oxygen species (ROS) generation. Another study by the same 
group (23) revealed that vaspin prevented tumor necrosis factor- $\alpha$ (TNF- $\alpha)$-induced intracellular adhesion molecule-1 via inhibiting ROS-dependent $N F-\kappa B$ and protein kinase $C-\theta$ (PKC $\theta$ ) activation in cultured rat vascular smooth muscle cells (SMCs). This suggested that vaspin had an inhibitory effect on the inflammatory state of SMCs. Furthermore, vaspin was able to suppress the expression of pro-inflammatory cytokines, including leptin, TNF- $\alpha$ and resistin in chronic hepatitis (24). However, another study by $\mathrm{Fu}$ et al (25) failed to demonstrate that vaspin inhibited TNF- $\alpha$-induced inflammation in human umbilical vein endothelial cells. These results strongly suggested that vaspin may act as an anti-inflammatory adipokine in metabolic diseases.

As a newly identified adipokine, the role of vaspin on chondrocytes and on the pathophysiology of OA remains to be elucidated. To the best of our knowledge, the present study is the first to investigate the effect of vaspin on chondrocytes. Our previous studies demonstrated that two important adipokines, leptin and apelin, had a catabolic effect on the articular cartilage by stimulating the expression of inflammatory and catabolic factors $(26,27)$. However, another adipokine adiponectin was suggested to have a protective role in the development of OA $(28,29)$. The present study aimed to reveal the precise role of this novel adipokine on chondrocytes.

The present study demonstrated that vaspin had no cytotoxicity when the concentration reached $500 \mathrm{ng} / \mathrm{ml}$. Following treatment with different concentrations of vaspin, no significant change was observed in the gene expression of catabolic factors MMP-2, MMP-9, ADAMTS-4, ADAMTS-5 and cathepsin. The present data indicated that vaspin alone in chondrocytes demonstrated neither catabolic nor anti-catabolic effects. However, low concentrations of vaspin significantly inhibited IL-1 $\beta$-induced MMP-2, MMP-9, ADAMTS-5 and cathepsin D but not ADAMTS-4 gene expression. Increased expression of MMP-2 and MMP-9 in pathological chondral, meniscal and synovial lesions of $\mathrm{OA}$ was considered to be important in OA pathophysiology (30). These two key MMPs, also termed gelatinase-A and gelatinase-B, could degrade numerous substrates, including collagens type IV, V, VII, X, cartilage-specific type XI, aggrecan core protein and significant collagen type II $(31,32)$. In addition, another important aggrecanase ADAMTS-5 (aggrecanase-2) was also suppressed markedly by vaspin in IL-1 $\beta$-induced chondrocytes. Notably, ADAMTS-4 and -5 were the most efficient aggrecanases and the most likely candidates to have a role in OA (33). In addition, low concentrations of vaspin also inhibited IL-1 $\beta$-induced production of cathepsin $\mathrm{D}$, which contribute to the proteolytic processing of the core protein of aggrecan in the initial stages of OA (34). These results suggested that low concentrations of vaspin have an anti-catabolic effect on chondrocytes in the presence of the proinflammatory agent IL-1 $\beta$, by inhibiting MMPs, aggrecanases and cathespin production.

Following treatment with different concentrations of vaspin, the inflammatory mediators $\mathrm{COX}-2, \mathrm{PGE}_{2}$ and iNOS secreted by chondrocytes decreased but not significantly, which suggested that vaspin may have an anti-inflammatory effect on the metabolism of chondrocytes. Furthermore, the production of COX-2, $\mathrm{PGE}_{2}$ and iNOS induced by IL-1 $\beta$ was significantly suppressed by vaspin in a dose-dependent manner in the present study. COX-2 and iNOS are two important inflammatory factors involved in the pathophysiology of OA, whose expression could be induced by IL-1 $\beta$ (35). COX-2 and iNOS led to the release of $\mathrm{PGE}_{2}$ and $\mathrm{NO}$ in chondrocytes, which has been demonstrated to increase MMP production and be implicated in joint pain in $\mathrm{OA}(36,37)$. $\mathrm{PGE}_{2}$ has also been implicated in the inflammation and cartilage degradation associated with OA $(38,39)$. Several studies have reported that vaspin exhibits anti-inflammatory properties in a variety of cell types $(23,24)$. The present study demonstrated for the first time, to the best of our knowledge, that vaspin prevented IL- $1 \beta$-induced $\mathrm{COX}-2, \mathrm{PGE}_{2}$ and iNOS production in rat normal chondrocytes, which suggested that vaspin has anti-inflammatory effects in the presence of the pro-inflammatory agent IL-1 $\beta$ on chondrocytes.

The current study also investigated the molecular mechanisms by which vaspin inhibited the inflammatory mediators in response to IL-1 $\beta$ in chondrocytes. The results suggested that vaspin suppressed IL- $1 \beta$-induced phosphorylation of $\mathrm{NF}-\kappa \mathrm{B}$ and inhibited IL-1 $\beta$-induced I $\mathrm{B}-\alpha$ degradation in chondrocytes. NF- $\kappa \mathrm{B}$ is a crucial signaling molecule in regulating the expression of inflammatory and catabolic factors in chondrocytes (40). The NF- $\kappa \mathrm{B}$ family exists in unstimulated cells bound to the $\mathrm{I} \kappa \mathrm{B}$ family protein, and the $\mathrm{NF}-\kappa \mathrm{B} / \mathrm{I} \kappa \mathrm{B}$ complex is not able translocate to the nucleus. I $\mathrm{B}$ degradation is tightly regulated by pro-inflammatory cytokines, including IL-1 $\beta$, which then phosphorylate NF- $\kappa \mathrm{B}$ and transport it from the cytoplasm to the nucleus, where it binds to the promoter regions of target genes, including inflammatory mediators and catabolic factors $(41,42)$. In the current study, IL-1 $\beta$ induced the phosphorylation of $\mathrm{NF}-\kappa \mathrm{B}$ in chondrocytes and this was inhibited by vaspin. These results were partly supported by Phalitakul et al (23), who revealed that vaspin significantly inhibited TNF- $\alpha$-induced phosphorylation of NF- $\kappa$ B in SMCs. Additionally, Li et al also reported that vaspin inhibited high glucose-induced SMC proliferation and chemokinesis by preventing ROS activation and mitogen-activated protein kinase (MAPK) phosphatidylinositol 3-kinase (PI3K/Akt) and $N F-\kappa B$ signaling (43). The previous studies together with the present study suggest that the anti-catabolic and anti-inflammatory effects of vaspin may partly be associated with the inhibition of $\mathrm{NF}-\kappa \mathrm{B}$ activation. However, the exact mechanism and the effects of vaspin on other signaling pathways, including PKC $\theta$, MAPK and PI3K/Akt remain to be elucidated. Further studies are required to elucidate the precise mechanism underlying the effect of vaspin on the chondrocyte inflammatory process.

In conclusion, the present study demonstrated that low concentrations of vaspin inhibited the IL-1 $\beta$-induced expression of catabolic factors, including MMP-2, MMP-9, ADAMTS-5 and cathepsin D. In addition, the present study revealed that the production of inflammatory mediators $\mathrm{COX}-2, \mathrm{PGE}_{2}$ and iNOS induced by IL-1 $\beta$ could be suppressed by vaspin in a dose-dependent manner in chondrocytes suggesting that vaspin has anti-catabolic and anti-inflammatory effects and that it may also be a potential protective cytokine during the development of OA. Furthermore, this role may be in part due to the inhibition of IL-1 $\beta$-induced activation of the $N F-\kappa B$ signaling pathway. 


\section{Acknowledgements}

This study was supported by the National Natural Science Foundation of China (no. 81201429).

\section{References}

1. Krasnokutsky S, Samuels J and Abramson SB: Osteoarthritis in 2007. Bull NYU Hosp Jt Dis 65: 222-228, 2007.

2. Kapoor M, Martel-Pelletier J, Lajeunesse D, Pelletier JP and Fahmi H: Role of proinflammatory cytokines in the pathophysiology of osteoarthritis. Nat Rev Rheumatol 71: 33-42, 2011

3. Goldring MB and Goldring SR: Osteoarthritis. J Cell Physiol 213: 626-634, 2007.

4. Yusuf E: Metabolic factors in osteoarthritis: obese people do not walk on their hands. Arthritis Res Ther 14: 123, 2012.

5. Cicuttini FM, Baker JR and Spector TD: The association of obesity with osteoarthritis of the hand and knee in women: a twin study. J Rheumatol 23: 1221-1226, 1996.

6. Yusuf E: Metabolic factors in osteoarthritis: obese people do not walk on their hands. Arthritis Res Ther 14: 123, 2012.

7. Bay-Jensen AC, Slagboom E, Chen-An P, et al: Role of hormones in cartilage and joint metabolism: understanding an unhealthy metabolic phenotype in osteoarthritis. Menopause 20: 578-586, 2013.

8. Hida K, Wada J, Eguchi J, et al: Visceral adipose tissue-derived serine protease inhibitor: a unique insulin-sensitizing adipocytokine in obesity. Proc Natl Acad Sci USA 102: 10610-10615, 2005.

9. Fain JN, Buehrer B, Bahouth SW, Tichansky DS and Madan AK: Comparison of messenger RNA distribution for 60 proteins in fat cells vs the nonfat cells of human omental adipose tissue. Metabolism 57: 1005-1015, 2008.

10. Klöting N, Berndt J, Kralisch S, et al: Vaspin gene expression in human adipose tissue: association with obesity and type 2 diabetes. Biochem Biophys Res Commun 339: 430-436, 2006.

11. Meyer-Hoffert U: Reddish, scaly, and itchy: how proteases and their inhibitors contribute to inflammatory skin diseases. Arch Immunol Ther Exp (Warsz) 57: 345-354, 2009.

12. Klöting N, Kovacs P, Kern M, et al: Central vaspin administration acutely reduces food intake and has sustained blood glucose-lowering effects. Diabetologia 54: 1819-1823, 2011.

13. Körner A, Neef M, Friebe D, et al: Vaspin is related to gender, puberty and deteriorating insulin sensitivity in children. Int J Obes (Lond) 35: 578-586, 2011.

14. Youn BS, Klöting N, Kratzsch J, et al: Serum vaspin concentrations in human obesity and type 2 diabetes. Diabetes 57: 372-377, 2008 .

15. Ozgen M, Koca SS, Dagli N, Balin M, Ustundag B and Isik A: Serum adiponectin and vaspin levels in rheumatoid arthritis Arch Med Res 41: 457-463, 2010.

16. Klaasen R, Herenius MM, Wijbrandts CA, et al: Treatment-specific changes in circulating adipocytokines: a comparison between tumour necrosis factor blockade and glucocorticoid treatment for rheumatoid arthritis. Ann Rheum Dis 71: 1510-1516, 2012.

17. Senolt L, Polanská M, Filková M, et al: Vaspin and omentin: new adipokines differentially regulated at the site of inflammation in rheumatoid arthritis. Ann Rheum Dis 69 1410-1411, 2010.

18. Kamio N, Kawato T, Tanabe N, et al: Vaspin attenuates RANKL-induced osteoclast formation in RAW264.7 cells. Connect Tissue Res 54: 147-152, 2013.

19. Choi SH, Hong ES and Lim S: Clinical implications of adipocytokines and newly emerging metabolic factors with relation to insulin resistance and cardiovascular health. Front Endocrinol (Lausanne) 4: 97, 2013.

20. Wada J: Vaspin: a novel serpin with insulin-sensitizing effects Expert Opin Investig Drugs 17: 327-333, 2008.

21. Kadoglou NP, Gkontopoulos A, Kapelouzou A, et al: Serum levels of vaspin and visfatin in patients with coronary artery disease-Kozani study. Clin Chim Acta 412: 48-52, 2011.

22. Phalitakul S, Okada M, Hara Y and Yamawaki H: Vaspin prevents methylglyoxal-induced apoptosis in human vascular endothelial cells by inhibiting reactive oxygen species generation. Acta Physiol (Oxf) 209: 212-219, 2013.
23. Phalitakul S, Okada M, Hara Y and Yamawaki H: Vaspin prevents TNF- $\alpha$-induced intracellular adhesion molecule-1 via inhibiting reactive oxygen species-dependent $\mathrm{NF}-\kappa \mathrm{B}$ and $\mathrm{PKC} \theta$ activation in cultured rat vascular smooth muscle cells. Pharmacol Res 64: 493-500, 2011.

24. Kukla M, Mazur W,Bułdak RJ and Zwirska-Korczala K: Potential role of leptin, adiponectin and three novel adipokines - visfatin, chemerin and vaspin - in chronic hepatitis. Mol Med 17: 1397-1410, 2011.

25. Fu BD, Yamawaki H, Okada M and Hara Y: Vaspin can not inhibit TNF- $\alpha$-induced inflammation of human umbilical vein endothelial cells. J Vet Med Sci 71: 1201-1207, 2009.

26. Bao JP, Chen WP, Feng J, Hu PF, Shi ZL and Wu LD: Leptin plays a catabolic role on articular cartilage. Mol Biol Rep 37: 3265-3272, 2010

27. Hu PF, Chen WP, Tang JL, Bao JP and Wu LD: Apelin plays a catabolic role on articular cartilage: in vivo and in vitro studies. Int J Mol Med 26: 357-363, 2010.

28. Uchida K, Urabe K, Naruse K, Ogawa Z, Mabuchi K and Itoman M: Hyperlipidemia and hyperinsulinemia in the spontaneous osteoarthritis mouse model, STR/Ort. Exp Anim 58: 181-187, 2009.

29. Chen TH, Chen L, Hsieh MS, Chang CP, Chou DT and Tsai SH: Evidence for a protective role for adiponectin in osteoarthritis. Biochim Biophys Acta 1762: 711-718, 2006.

30. Hsieh YS, Yang SF, Chu SC, et al: Expression changes of gelatinases in human osteoarthritic knees and arthroscopic debridement. Arthroscopy 20: 482-488, 2004.

31. Birkedal-Hansen H, Moore WG, Bodden MK, et al: Matrix metalloproteinases: a review. Crit Rev Oral Biol Med 4: 197-250, 1993.

32. Kozaci LD, Buttle DJ and Hollander AP: Degradation of type II collagen, but not proteoglycan, correlates with matrix metalloproteinase activity in cartilage explant cultures. Arthritis Rheum 40: 164-174, 1997.

33. Fushimi K, Troeberg L, Nakamura H, Lim NH and Nagase H: Functional differences of the catalytic and non-catalytic domains in human ADAMTS-4 and ADAMTS-5 in aggrecanolytic activity. J Biol Chem 283: 6706-6716, 2008.

34. Handley CJ, Mok MT, Ilic MZ, Adcocks C, Buttle DJ and Robinson HC: Cathepsin D cleaves aggrecan at unique sites within the interglobular domain and chondroitin sulfate attachment regions that are also cleaved when cartilage is maintained at acid pH. Matrix Biol 20: 543-553, 2001.

35. Chabane N, Zayed N, Afif H, et al: Histone deacetylase inhibitors suppress interleukin-1 $\beta$-induced nitric oxide and prostaglandin E2 production in human chondrocytes. Osteoarthritis Cartilage 16: 1267-1274, 2008.

36. Salvemini D, Misko TP, Masferrer JL, Seibert K, Currie MG and Needleman P: Nitric oxide activates cyclooxygenase enzymes. Proc Natl Acad Sci USA 90: 7240-7244, 1993.

37. Sasaki K, Hattori T, Fujisawa T, Takahashi K, Inoue H and Takigawa M: Nitric xide mediates interleukin-1-induced gene expression of matrix metalloproteinases and basic fibroblast growth factor in cultured rabbit articular chondrocytes. J Biochem 123: 431-439, 1998.

38. Amin AR, Attur M, Patel RN, et al: Superinduction of cyclooxygenase-2 activity in human osteoarthritis-affected cartilage. Influence of nitric oxide. J Clin Invest 99: 1231-1237, 1997.

39. Wang P, Zhu F and Konstantopoulos K: Prostaglandin E2 induces interleukin-6 expression in human chondrocytes via cAMP/protein kinase A- and phosphatidylinositol 3-kinase-dependent NF- $\kappa \mathrm{B}$ activation. Am J Physiol Cell Physio 298: C1445-C1456, 2010.

40. Vincenti MP and Brinckerhoff CE: Transcriptional regulation of collagenase (MMP-1, MMP-13) genes in arthritis: integration of complex signaling pathways for the recruitment of gene-specific transcription factors. Arthritis Res 4: 157-164, 2002.

41. Tian B and Brasier AR: Identification of a nuclear factor $\kappa \mathrm{B}$-dependent gene network. Recent Prog Horm Res 58: 95-130, 2003.

42. Hayden MS and Ghosh S: Signaling to NF-кB. Genes Dev 18: 2195-2224, 2004

43. Li H, Peng W, Zhuang J, et al: Vaspin attenuates high glucose-induced vascular smooth muscle cells proliferation and chemokinesis by inhibiting the MAPK, PI3K/Akt, and NF- $\mathrm{BB}$ signaling pathways. Atherosclerosis 228: 61-68, 2013. 